Article

\title{
Dynamic Response of $\mathrm{CoSb}_{2} \mathrm{O}_{6}$ Trirutile-Type Oxides in a $\mathrm{CO}_{2}$ Atmosphere at Low-Temperatures
}

\author{
Alex Guillén-Bonilla ${ }^{1}{ }^{1}$, Verónica-María Rodríguez-Betancourtt ${ }^{1}$, Martín Flores-Martínez ${ }^{1}$, \\ Oscar Blanco-Alonso ${ }^{2}$, Juan Reyes-Gómez ${ }^{3}$, Lorenzo Gildo-Ortiz ${ }^{4}$ and Héctor Guillén-Bonilla ${ }^{4}$
}

1 Materials Science Graduate School, CUCEI (Centro Universitario de Ciencias Exactas e Ingenierías), University of Guadalajara, Blvd. M. García Barragán 1421, Guadalajara, Jalisco 44410, Mexico; E-Mails: veronica.rodriguez@red.cucei.udg.mx (V.-M.R.-B.); doctorado.materiales@cucei.udg.mx (M.F.-M.)

2 Physics Department, CUCEI (Centro Universitario de Ciencias Exactas e Ingenierías), University of Guadalajara, Blvd. M. García Barragán 1421, Guadalajara, Jalisco 44410, Mexico;

E-Mail: oscar.blanco@cucei.udg.mx

3 Faculty of Science, University of Colima, Bernal Díaz del Castillo 340, Colima, Colima 28045, Mexico; E-Mail: reyesgj@ucol.mx

4 Faculty of Chemical Sciences, University of Colima, Km 9 Carretera Colima-Coquimatlán, Coquimatlán 28400, Colima, Mexico; E-Mails: lorenzo.gildo@gmail.com (L.G.-O.); hguillenbonilla@gmail.com (H.G.-B.)

* Author to whom correspondence should be addressed; E-Mail: alexguillenbonilla@gmail.com; Tel.: +52-33-38-36-45-00 (ext. 27941); Fax: +52-33-38-36-45-02.

Received: 23 July 2014; in revised form: 17 August 2014 / Accepted: 20 August 2014 /

Published: 26 August 2014

Abstract: Experimental work on the synthesis of the $\mathrm{CoSb}_{2} \mathrm{O}_{6}$ oxide and its $\mathrm{CO}_{2}$ sensing properties is presented here. The oxide was synthesized by a microwave-assisted colloidal method in presence of ethylenediamine after calcination at $600{ }^{\circ} \mathrm{C}$. This $\mathrm{CoSb}_{2} \mathrm{O}_{6}$ oxide crystallized in a tetragonal structure with cell parameters $a=4.6495$ and $c=9.2763 \AA$, and space group $P 4_{2} / \mathrm{mnm}$. To prove its physical, chemical and sensing properties, the oxide was subjected to a series of tests: Raman spectroscopy, Scanning Electron Microscopy (SEM) and impedance $(Z)$ measurements. Microstructures, like columns, bars and hollow hemispheres, were observed. For the $\mathrm{CO}_{2}$ sensing test, a thick film of $\mathrm{CoSb}_{2} \mathrm{O}_{6}$ was used, measuring the impedance variations on the presence of air/ $\mathrm{CO}_{2}$ flows $(0.100 \mathrm{sccm} / 0.100 \mathrm{sccm})$ using $\mathrm{AC}$ (alternating current) signals in the frequency-range 
$0.1-100 \mathrm{kHz}$ and low relative temperatures $\left(250\right.$ and $\left.300{ }^{\circ} \mathrm{C}\right)$. The $\mathrm{CO}_{2}$ sensing results were quite good.

Keywords: sensing properties; $\mathrm{CoSb}_{2} \mathrm{O}_{6}$; trirutile; chemical synthesis

\section{Introduction}

Due to environmental concerns, the constant monitoring of the gases emitted to the atmosphere is highly important. Therefore, intense research on the gas-sensors area is carried out nowadays, especially regarding sensors based on semiconductor materials, like the oxides $\mathrm{SnO}_{2}, \mathrm{ZnO}, \mathrm{TiO}_{2}, \mathrm{WO}_{3}$, $\mathrm{LaFeO}_{3}$ and $\mathrm{CoAl}_{2} \mathrm{O}_{4}$ [1-7]. Such materials show interesting sensing properties, remaining at the same time chemically stable in the presence of polluting gases. In recent years, oxides with a trirutile-type structure, like $\mathrm{CoSb}_{2} \mathrm{O}_{6}[8,9]$ and $\mathrm{ZnSb}_{2} \mathrm{O}_{6}[10,11]$, are being studied for gas-sensing applications with very good results. These results are mainly attributed to the nano-sized structure of the trirutile oxides, which therefore determines the best synthesis process (route) to produce them [9]. The ceramic method for the synthesis of oxides has been extensively used; however, this conventional process involves some disadvantages, for instance, it is necessary to heat the sample at elevated temperatures for a long time. Such treatment results in inhomogeneous materials, no control of the particle size and a decrease of the surface area. In order to overcome these problems, wet chemical routes can also be successfully employed, at relative low temperatures, yielding nanoparticles with unique microstructural features [12-14].

In addition, the response of a sensor in polluting gases atmospheres is strongly related to the chemical reactions occurring on the oxide surface; therefore, the microstructure determines the conversion efficiency of chemical interactions into electrical signals. So, it is very important to synthesize materials with optimal morphologies [1,15]. In this work we implemented a chemical synthesis route (the microwave-assisted colloidal method) to produce the $\mathrm{CoSb}_{2} \mathrm{O}_{6}$ oxide for gas sensing purposes. The employed synthesis route was found very convenient because a good stoichiometry control was possible, influencing positively on the microstructural characteristics of the oxide.

\section{Experimental Section}

\subsection{Synthesis of Trirutile-Type $\mathrm{CoSb}_{2} \mathrm{O}_{6}$ Oxide}

The trirutile-type structure $\mathrm{CoSb}_{2} \mathrm{O}_{6}$ oxide was synthesized based on the procedure described in $[8,9]$. However, in this work, these reagents were used: $\mathrm{SbCl}_{3}$ (Sigma-Aldrich), $\mathrm{Co}\left(\mathrm{NO}_{3}\right)_{2} \cdot 6 \mathrm{H}_{2} \mathrm{O}$ (Mallinckrodt), $1 \mathrm{~mL}$ of ethylenediamine, and $5 \mathrm{~mL}$ of ethanol (Golden Bell). The resulting solution was evaporated by means of a microwave oven (JES769WK General Electric) at low power (180 W at 10-20 s intervals; the absorbed energy was calculated to be close to $85 \mathrm{~kJ}$ ). The obtained precursor material was dried at $200{ }^{\circ} \mathrm{C}$ in static air for $8 \mathrm{~h}$, then calcined in a muffle (Novatech) at $600{ }^{\circ} \mathrm{C}$ in static air for $6 \mathrm{~h}$. In this process, a heating rate of $100{ }^{\circ} \mathrm{C} / \mathrm{h}$ was employed. 


\subsection{Characterization of $\mathrm{CoSb}_{2} \mathrm{O}_{6}$ Powders}

The calcined powders were analyzed by X-ray diffraction (XRD) at room temperature, using a D500 Siemens diffractometer (Siemens, Munich, Germany) with a $\mathrm{Cu}-\mathrm{K} \alpha$ radiation $(\lambda=0.1518 \mathrm{~nm})$. The $2 \theta$ scanning range was from $10^{\circ}$ to $70^{\circ}$ with a velocity of $1^{\circ} \mathrm{min}^{-1}$. The powders were also analyzed by Raman spectroscopy (Renishaw, Inc, Schaumburg, IL, USA) using a 1000B microRaman Renishaw system, calibrated with a silicon semiconductor with its characteristic Raman peak at $520 \mathrm{~cm}^{-1}$. The laser (excitation wavelength of $830 \mathrm{~nm}$ ) was focused on the surface of the powders (spot size of approximately $20 \mu \mathrm{m}$ ) by means of a Leica optical microscope (DMLM; Leica microsystems, Deerfield, IL, USA) integrated to the microRaman system. The radiation energy on the sample was $4.5 \mathrm{~mW} 60$ s. The morphology of the $\mathrm{CoSb}_{2} \mathrm{O}_{6}$ powders was analyzed by scanning electron microscopy (JEOL JSM-6390LV; Jeol, Inc., Dearborn, MI, USA).

The electrical characterization was made through dynamic tests of the impedance variation using a thick film made of oxide powders, which were set inside of a controlled tube-type furnace at temperatures of 250 and $300{ }^{\circ} \mathrm{C}$. The impedance measurements were made by the two-tips technique using a computer controlled (with LabView 8.6, National Instruments) (Agilent 4263B device; Agilent Technologies, Inc, Santa Clara, CA, USA). The flow of the synthetic air/ $\mathrm{CO}_{2}$ gases was controlled by a MKS 647C controller (MKS Instruments, Inc, Andover, MA, USA).

\section{Results and Discussion}

\subsection{X-Ray Diffraction Analysis}

Figure 1 shows an X-ray diffraction pattern of the powders prepared by the above described method.

Figure 1. X-ray diffraction pattern of $\mathrm{CoSb}_{2} \mathrm{O}_{6}$ powders calcined at $600{ }^{\circ} \mathrm{C}$ in air.

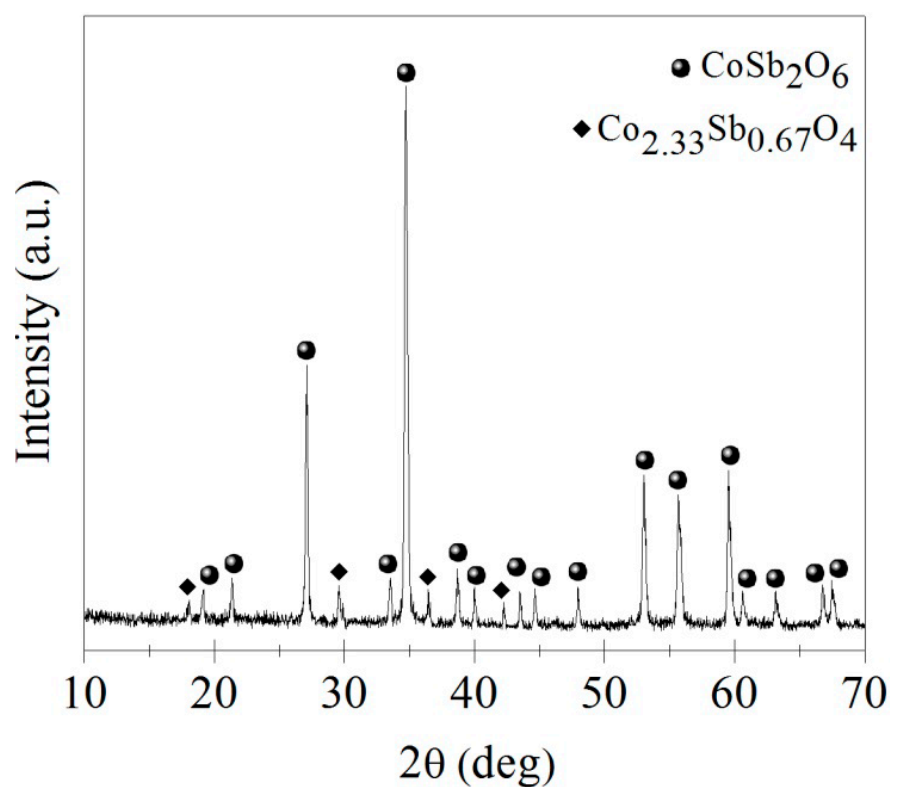


The diffractogram shows the presence of the main phase corresponding to $\mathrm{CoSb}_{2} \mathrm{O}_{6}$, which was identified using the file ICDD 203094. According to this card, the $\mathrm{CoSb}_{2} \mathrm{O}_{6}$ oxide crystallized in a tetragonal structure with cell parameters $a=4.6495$ and $c=9.2763 \AA$, and space group $\mathrm{P}_{2} / \mathrm{mnm}$ (136) [16], which indicates that the oxide belongs to the family of trirutile-type structures [17]. In addition, the width of the peaks in the diffraction spectra is an indication of crystals of nanometric size; the low noise level indicates that the sample possesses a high crystallinity [18]. The estimated crystal size according to the Scherrer equation [19] for the $\mathrm{CoSb}_{2} \mathrm{O}_{6}$ powders was around $41 \mathrm{~nm}$. Furthermore, low intensity peaks identified through the ICDD 87234 file, reveal a secondary phase: $\mathrm{Co}_{2.33} \mathrm{Sb}_{0.67} \mathrm{O}_{4}$ [9], localized on the angular positions $2 \theta=17.8^{\circ}, 2 \theta=29.5^{\circ}, 2 \theta=36.2^{\circ}$, and $2 \theta=42^{\circ}$.

Several other synthesis methods have been used for the preparation of oxides with trirutile-type structure. Larcher et al. [20] synthesized trirutile-type $\mathrm{ASb}_{2} \mathrm{O}_{6}$ materials ( $\mathrm{A}=\mathrm{Ni}, \mathrm{Cu}, \mathrm{Co}$ ), following the solid-state reaction method, obtaining the structures at $800{ }^{\circ} \mathrm{C}$. Michel et al. [21] obtained the $\mathrm{CoSb}_{2} \mathrm{O}_{6}$ oxide employing the solution-polymerization method at $700{ }^{\circ} \mathrm{C}$. From the present work, and comparing with other studies, it can be stated that the obtention of the $\mathrm{CoSb}_{2} \mathrm{O}_{6}$ oxide is very feasible at temperatures significantly lower than those used by the authors above mentioned, by means of the synthesis route proposed here (the microwave-assisted colloidal method).

\subsection{Raman Spectroscopy Analysis}

The Raman analysis (Figure 2 and Table 1) shows the vibrations modes $A_{1 g}, B_{1 g}, B_{2 g}$ and $E_{g}$ at the range 190-800 $\mathrm{cm}^{-1}$. Band $v_{1}$ has a mean intensity $\sim 194 \pm 3 \mathrm{~cm}^{-1}$ and is due to the vibrations of the crystalline network with $\mathrm{A}_{1 \mathrm{~g}}$ symmetry. Band $v_{2}$, at $\sim 478 \pm 3 \mathrm{~cm}^{-1}$, is due to the deformation vibration of the Co-O bond, also with $\mathrm{A}_{1 \mathrm{~g}}$ symmetry. Band $v_{3}$, at $\sim 518 \pm 3 \mathrm{~cm}^{-1}$, can be attributed to the combination of the stretching and coupling vibrations of the Sb-O bonds, with symmetry $\mathrm{E}_{\mathrm{g}}$. Band $v_{4}$, at $\sim 617 \pm 3 \mathrm{~cm}^{-1}$, is due to the asymmetric stretching vibration of the $\mathrm{Sb}-\mathrm{O}$ bond, with symmetry $\mathrm{E}_{\mathrm{g}}$. Band $v_{5}$, at $\sim 641 \pm 3 \mathrm{~cm}^{-1}$, showing a high intensity, is due to the symmetric stretching vibration of the Sb-O bond, with $E_{g}$ symmetry. These results are in agreement with [22] and [23], and support the correct characterization of the oxide.

Figure 2. Raman spectrum of $\mathrm{CoSb}_{2} \mathrm{O}_{6}$ powders calcined at $600{ }^{\circ} \mathrm{C}$ in air.

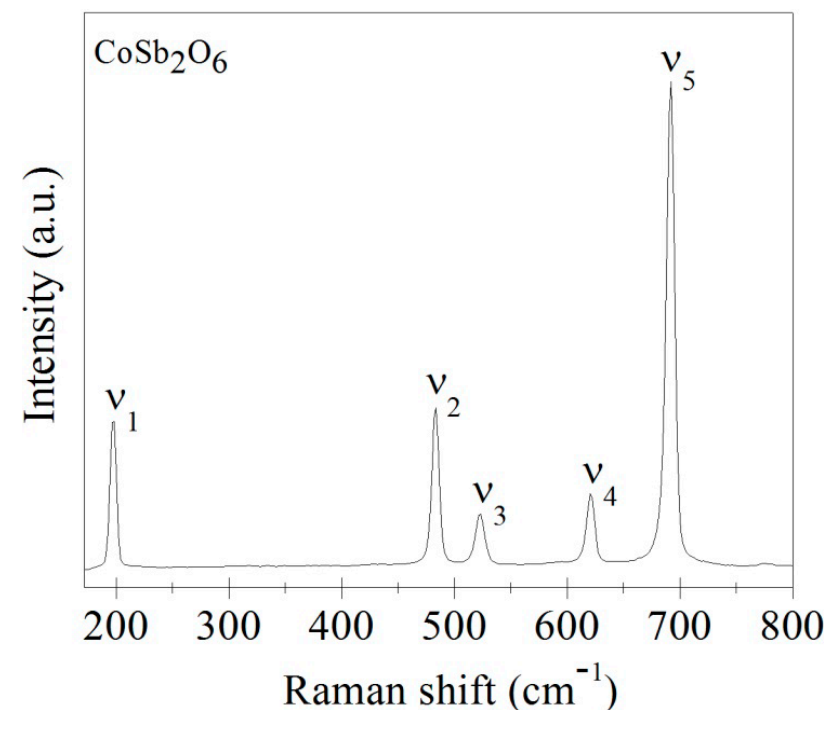


Table 1. Vibration modes of the $\mathrm{CoSb}_{2} \mathrm{O}_{6}$ oxide.

\begin{tabular}{ccccc}
\hline Mode & Raman Displacement $\left(\mathbf{c m}^{-\mathbf{1}}\right)$ & Symmetry & Vibration Type & Molecular Bond \\
\hline $\boldsymbol{v}_{\mathbf{1}}$ & $\sim 194 \pm 3$ & $\mathrm{~A}_{1 \mathrm{~g}}$ & Crystalline network & \\
$\boldsymbol{v}_{\mathbf{2}}$ & $\sim 478 \pm 3$ & $\mathrm{~A}_{1 \mathrm{~g}}$ & Deformation & $\mathrm{Co}-\mathrm{O}$ \\
$\boldsymbol{v}_{\mathbf{3}}$ & $\sim 518 \pm 3$ & $\mathrm{E}_{\mathrm{g}}$ & Stretching and Coupling & $\mathrm{Sb}_{\mathrm{O}}^{-} \mathrm{Sb}$ \\
$\boldsymbol{v}_{\mathbf{4}}$ & $\sim 617 \pm 3$ & $\mathrm{E}_{\mathrm{g}}$ & Stretching (asymmetric) & $\mathrm{Sb}-\mathrm{O}$ \\
$\boldsymbol{v}_{\mathbf{5}}$ & $\sim 641 \pm 3$ & $\mathrm{E}_{\mathrm{g}}$ & Stretching & (symmetric) \\
\hline
\end{tabular}

\subsection{Scanning Electron Microscopy Analysis}

Figure 3 shows photomicrographs of the $\mathrm{CoSb}_{2} \mathrm{O}_{6}$ oxide at several magnifications: (a) 350X, (b) 370X, and (c) 700X. The discerned particle shapes are rectangular micro-bars with sizes: base $\sim 28.5 \mu \mathrm{m}$, length $\sim 42 \mu \mathrm{m}$ and height $\sim 13 \mu \mathrm{m}$. Around these bars, some smaller structures in form of micro-rods, growing in different directions, are also discernible. The micro-rods growth, with an estimated diameter of $\sim 2.7 \mu \mathrm{m}$, is attributed to the increasing of the temperature and the effects caused by the ethylenediamine. These micro-rods tend to aggregate to form a hollow hemisphere (see image b). The granulate surface of the micro-rods is probably due to the released gases from organic material during the thermal decomposition in the oxide's synthesis [24]. The size distribution of the micro-rods (also shown in Figure 3d) depicts a length range of 6-24 $\mu \mathrm{m}$ with a standard deviation of $3.4 \mu \mathrm{m}$ and an average length of $\sim 12.7 \mu \mathrm{m}$. The role of ethylenediamine in the formation of 1D structures of II-VI semiconductors, like nanorods and nanowires, has been discussed in previous works [25,26]. The ethylenediamine is incorporated first into the inorganic framework and then escapes from it to form particles of desired morphologies [26]. In this work, we found that the presence of ethylenediamine in the $\mathrm{CoSb}_{2} \mathrm{O}_{6}$ synthesis leads to the growth of micro-rods. In fact, we reported in a previous work [27] the obtention of trirutile-type $\mathrm{MgSb}_{2} \mathrm{O}_{6}$ with different morphologies, micro-rods and micro-plates among them, by the use of ethylenediamine.

Figure 3. SEM (scanning electron microscopy) images of $\mathrm{CoSb}_{2} \mathrm{O}_{6}$ powders at different magnifications: (a) 350X; (b) 370X; and (c) 700X; (d) length distribution of the micro-rods.

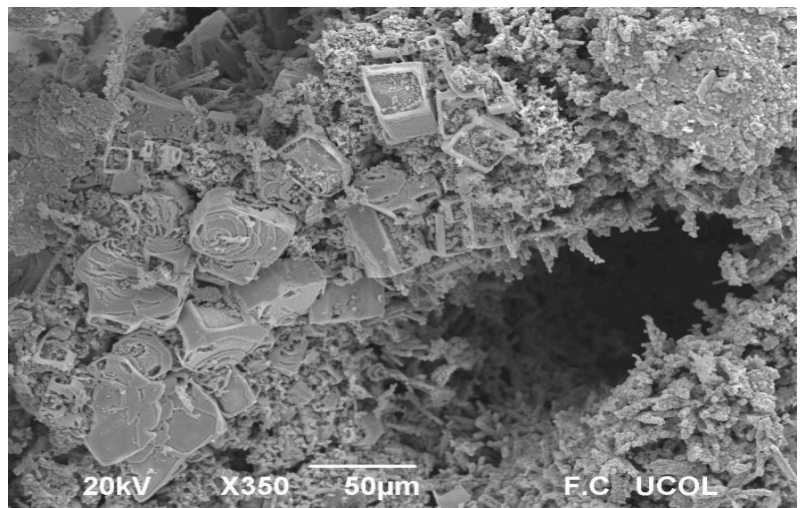

(a)

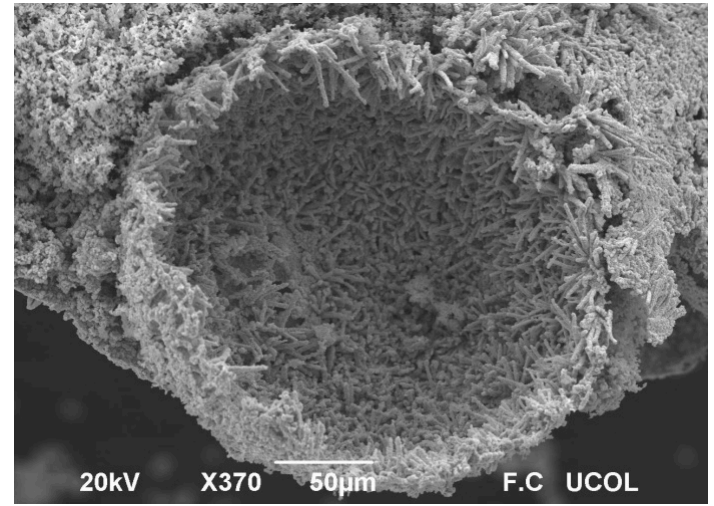

(b) 
Figure 3. Cont.

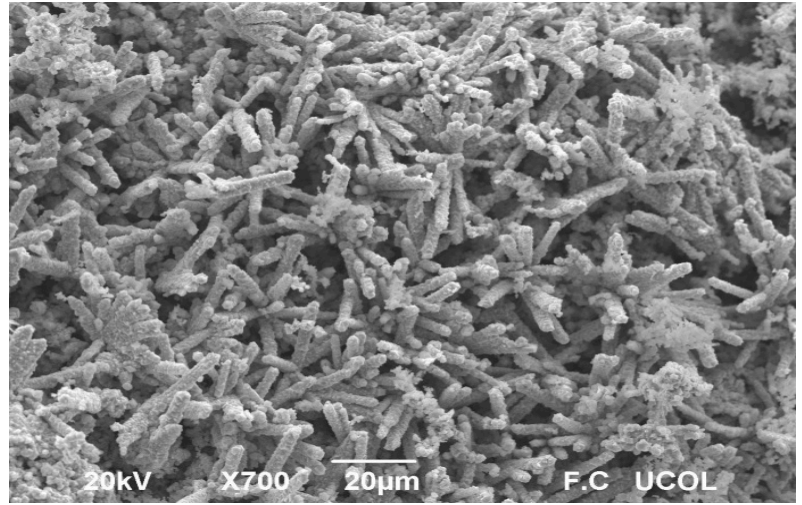

(c)

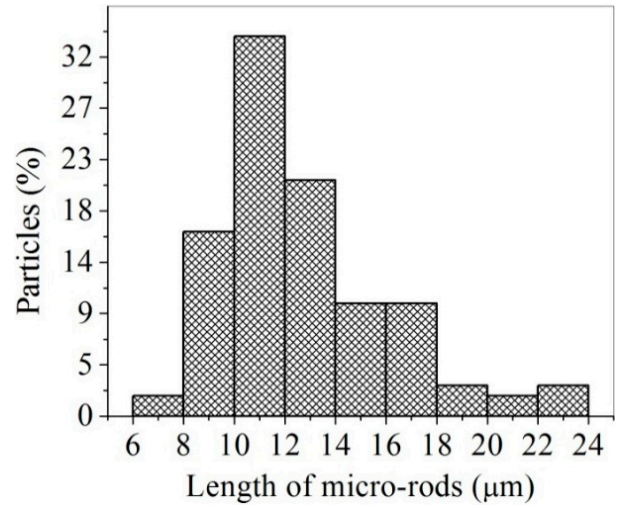

(d)

On the other hand, the preparation of different inorganic compounds by means of colloidal routes has been widely studied by Matijevic [28]. Some authors report the obtention of morphologies similar to those here reported, which originate from the growth process of stable nuclei of the colloidal systems $[28,29]$. These morphologies are in agreement with the crystallization principles proposed by LaMer and Dinegar [9,24,27,30].

\subsection{Impedance Measurements and Gas Sensing Properties}

To test the gas sensing properties of the $\mathrm{CoSb}_{2} \mathrm{O}_{6}$ oxide, a thick film (thickness $\sim 500 \mu \mathrm{m}$ ) was employed for measuring its impedance variation in presence of air $/ \mathrm{CO}_{2}$ flows $(0.100 \mathrm{sccm} / 0.100 \mathrm{sccm})$. Experiments at four frequencies (AC (alternating current) signals) were conducted in this study: 0.1, 1, 10 and $100 \mathrm{kHz}$, and at two different temperatures, namely, 250 and $300{ }^{\circ} \mathrm{C}$. The process to perform the dynamic response experiments consisted of three stages: (1) for each frequency and temperature, synthetic air was flowed over the film's surface during approximately $5 \mathrm{~min}$ in order to stabilize it; (2) a $\mathrm{CO}_{2}$ flow was applied on the material, recording the impedance ( $|Z|$ ) variations; (3) after one minute, synthetic air was flowed again over the thick film, returning the impedance $|Z|$ to the initial state. Figure 4 shows the dynamic tests results of the $\mathrm{CoSb}_{2} \mathrm{O}_{6}$ oxide at $250{ }^{\circ} \mathrm{C}$, and Table 2 shows the calculated variations. In all four tests $(0.1,1,10$ and $100 \mathrm{kHz})$, the magnitude of the impedance $(|Z|)$ changes in an alternating manner when the gas flow changes from air to $\mathrm{CO}_{2}$. These results reveal that the material exhibits sensitivity and repeatability in $\mathrm{CO}_{2}$ detection. In particular, at the $0.1 \mathrm{kHz}$ frequency, the change of the magnitude $|Z|$ was $\sim 3.23 \mathrm{k} \Omega$ on average (Figure 4a); while at the $1 \mathrm{kHz}$ frequency, the recorded change was $\sim 2.91 \mathrm{k} \Omega$ on average (Figure $4 \mathrm{~b}$ ). On the other hand, at the $10 \mathrm{kHz}$ frequency, the magnitude of the impedance changes $\sim 2.43 \mathrm{k} \Omega$ on average (Figure $4 \mathrm{c}$ ); however, using a high frequency of $100 \mathrm{kHz}$, the magnitude of the impedance is reduced to an average value of $\sim 1.71 \mathrm{k} \Omega$ (Figure 4d).

In addition, Figure 4 shows the fast response and recovery times recorded during the exposure to the $\mathrm{CO}_{2}$ gas at $250{ }^{\circ} \mathrm{C}$. The response times, measured at $90 \%$ of the full response, were $22.38,21.56$, 20.32 and $18.19 \mathrm{~s}$ at the frequencies $0.1,1,10$ and $100 \mathrm{kHz}$, respectively, while the recorded recovery times were 21.36, 20.06, 19.06 and $17.95 \mathrm{~s}$ at the same frequencies, respectively (See Table 2). From 
these results, $\mathrm{CoSb}_{2} \mathrm{O}_{6}$ thick films respond faster and with a shorter recovery time at the higher frequency $(100 \mathrm{kHz})$; however, upon increasing the frequency, smaller $|Z|$ values were registered.

Figure 4. Dynamic response of the $\mathrm{CoSb}_{2} \mathrm{O}_{6}$ oxide subjected to $\mathrm{CO}_{2}$ flows at $250{ }^{\circ} \mathrm{C}$ and different frequencies: (a) $0.1 \mathrm{kHz}$; (b) $1 \mathrm{kHz}$; (c) $10 \mathrm{kHz}$; and (d) $100 \mathrm{kHz}$.

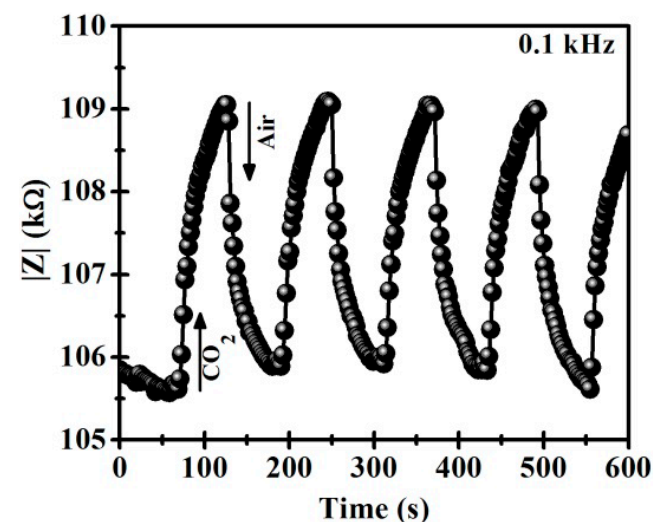

(a)

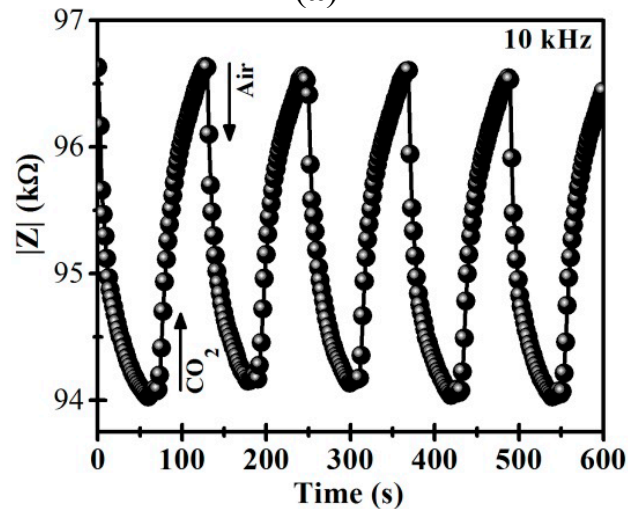

(c)

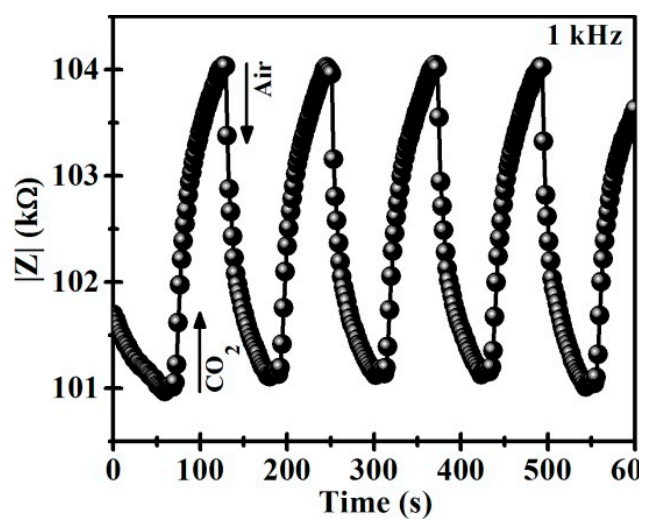

(b)

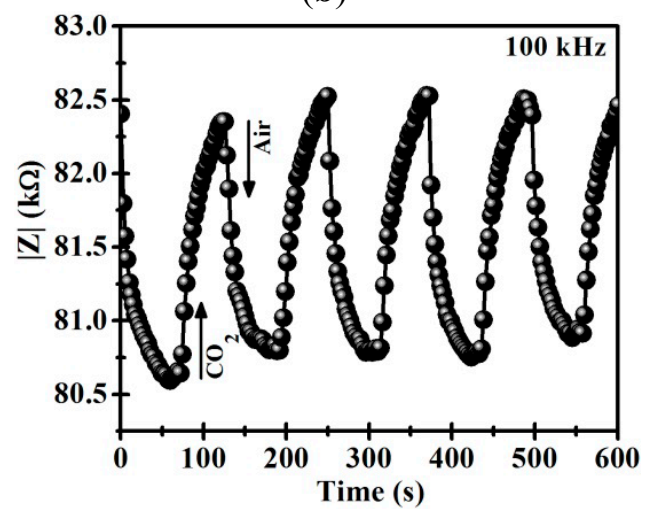

(d)

Table 2. Variations of the impedance measurement at $250{ }^{\circ} \mathrm{C}$.

\begin{tabular}{|c|c|c|c|}
\hline Frequency $(\mathrm{kHz})$ & Mean Impedance $(\mathrm{k} \Omega)$ & Response Time (s) & Recovering Time (s) \\
\hline 0.1 & 3.23 & 22.38 & 21.36 \\
\hline 1 & 2.91 & 21.56 & 20.06 \\
\hline 10 & 2.43 & 20.32 & 19.06 \\
\hline 100 & 1.71 & 18.19 & 17.95 \\
\hline
\end{tabular}

Figure 5 shows the results of the dynamic tests on the $\mathrm{CoSb}_{2} \mathrm{O}_{6}$ oxide at $300{ }^{\circ} \mathrm{C}$ with the same frequencies and gases flows, and the calculated variations are shown in Table 3. Similar tendencies to those shown in Figure 4 were recorded. However, at $300{ }^{\circ} \mathrm{C}$, the changes of the magnitude $|Z|$ were $\sim 1.29, \sim 1.18, \sim 1.09$ and $\sim 0.921 \mathrm{k} \Omega$, at the frequencies $0.1,1,10$ and $100 \mathrm{kHz}$, respectively. In addition, the response and recovery times were reduced to values less than $20 \mathrm{~s}$ due to the effect of the temperature. In this case, the response times were 17.32, 16.30, 15.00 and $14.18 \mathrm{~s}$, while the recovery times were $16.18,15.00,13.93$ and $13.00 \mathrm{~s}$ at the same frequencies, respectively (see Table 3). Clearly, at higher temperatures and frequencies applied, the $\mathrm{CoSb}_{2} \mathrm{O}_{6}$ sensor exhibits faster response and shorter recovery times. 
Figure 5. Dynamic response of the $\mathrm{CoSb}_{2} \mathrm{O}_{6}$ oxide subjected to $\mathrm{CO}_{2}$ flows at $300{ }^{\circ} \mathrm{C}$ and different frequencies: (a) $0.1 \mathrm{kHz}$; (b) $1 \mathrm{kHz}$; (c) $10 \mathrm{kHz}$; and (d) $100 \mathrm{kHz}$.

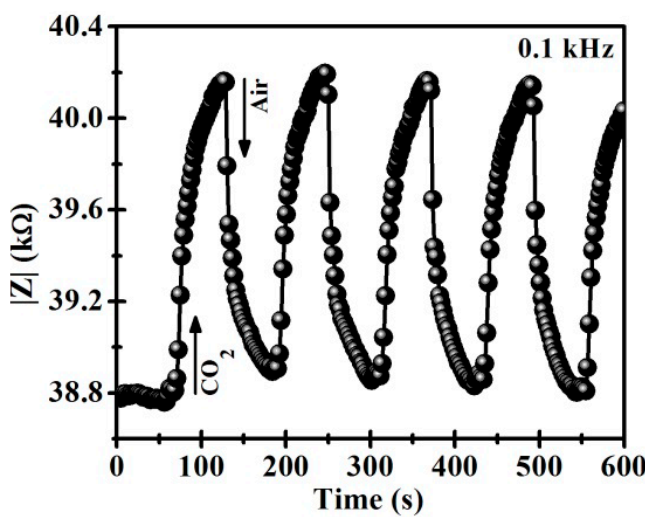

(a)

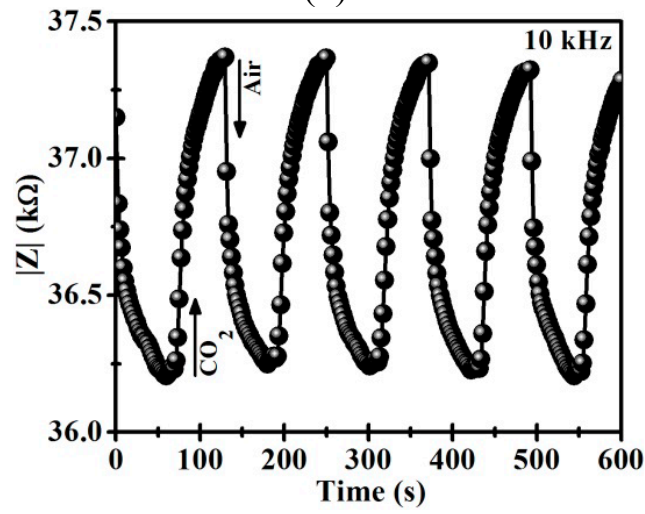

(c)

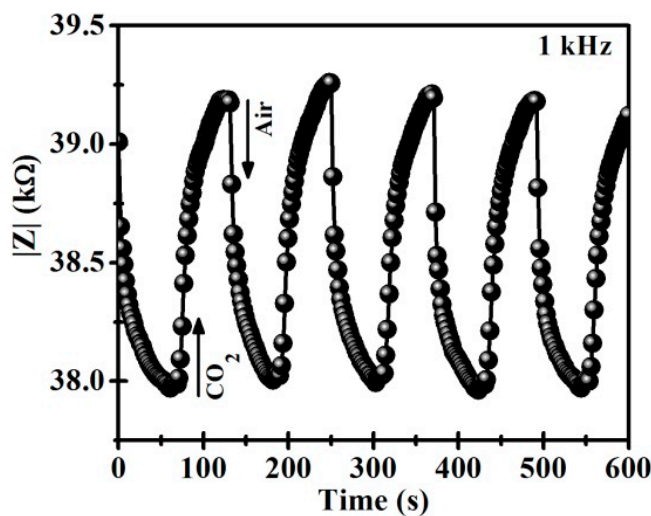

(b)

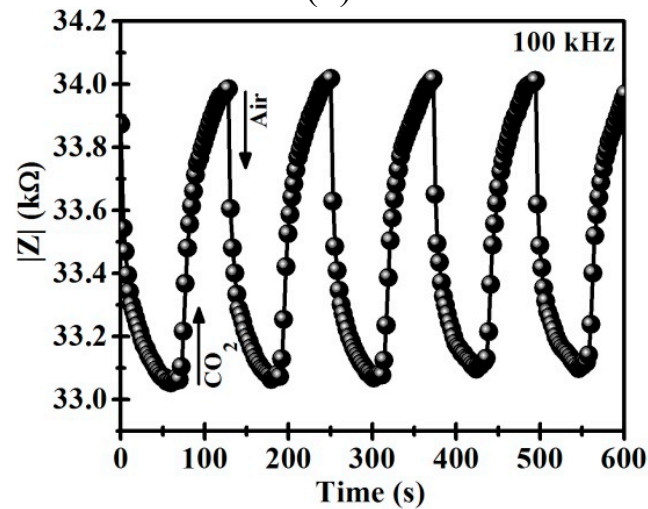

(d)

Table 3. Variations of the impedance measurement at $300^{\circ} \mathrm{C}$.

\begin{tabular}{cccc}
\hline Frequency $(\mathbf{k H z})$ & Mean Impedance $(\mathbf{k} \boldsymbol{\Omega})$ & Response Time (s) & Recovering Time (s) \\
\hline 0.1 & 1.29 & 17.32 & 16.18 \\
1 & 1.18 & 16.30 & 15.00 \\
10 & 1.09 & 15.00 & 13.93 \\
100 & 0.921 & 14.18 & 13.00 \\
\hline
\end{tabular}

To discern the effects of frequency and temperature on the $\mathrm{CoSb}_{2} \mathrm{O}_{6}$ ability to detect air/ $\mathrm{CO}_{2}$, Figure 6 shows graphically the above mentioned variations. Clearly, increasing the frequency and the temperature, the impedance drops considerably, which is a characteristic of semiconductor materials. At $250{ }^{\circ} \mathrm{C}$, the average $|Z|$ is $2.52 \mathrm{k} \Omega$ and at $300{ }^{\circ} \mathrm{C}$, it is $1.12 \mathrm{k} \Omega$. The oxide therefore behaves like a low-pass filter and can be modeled as a parallel RC circuit (see Figure 7). This circuit is made up of the alternating current $(\mathrm{AC})$ source, a resistance $(\mathrm{R})$ and a capacitor $(\mathrm{C})$ [8]. In addition, the behavior of the dynamic response obtained at 250 and $300{ }^{\circ} \mathrm{C}$ can be reproducible. This suggests that this material can reliably be applied as a gas sensor under air/ $\mathrm{CO}_{2}$ flows [31]. 
Figure 6. Impedance $|\mathrm{Z}|$ vs. frequency tests of the $\mathrm{CoSb}_{2} \mathrm{O}_{6}$ oxide at (a) $250{ }^{\circ} \mathrm{C}$ and (b) $300{ }^{\circ} \mathrm{C}$ with air $/ \mathrm{CO}_{2}$ flows.

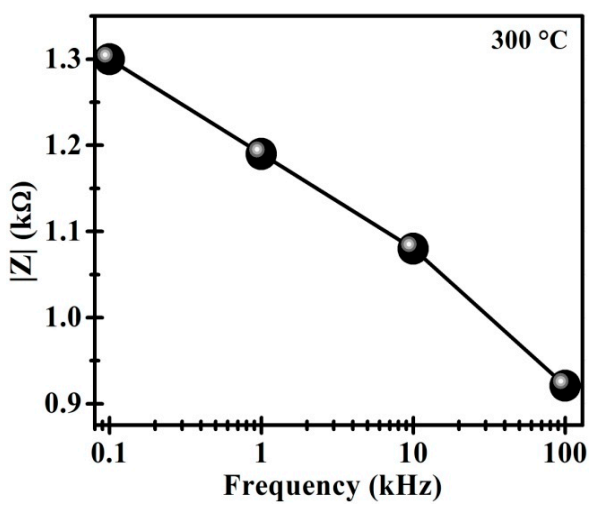

(a)

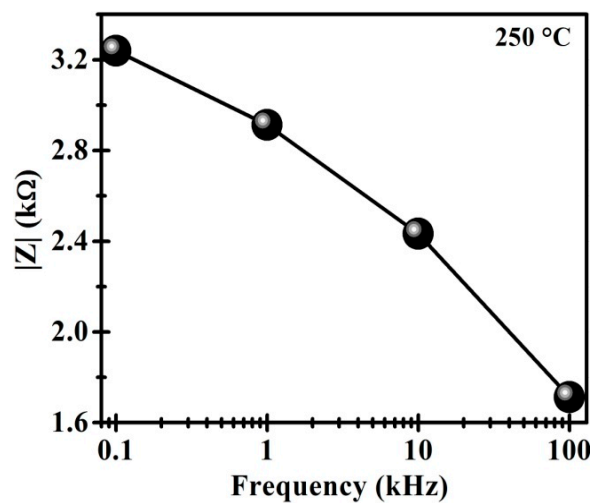

(b)

Figure 7. Equivalent RC parallel circuit for the $\mathrm{CoSb}_{2} \mathrm{O}_{6}$ sensor.

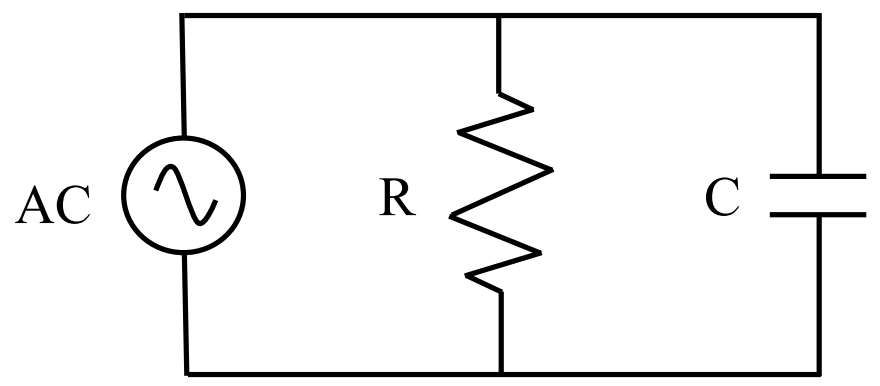

Comparing the results of Figures 4 and 5 with those reported in previous works corresponding to the $\mathrm{CoSb}_{2} \mathrm{O}_{6}$ oxide, a better performance as gas sensor was obtained in the present work. For example, nanostructured $\mathrm{CoSb}_{2} \mathrm{O}_{6}$ microspheres have been synthesized employing a non-aqueous method in presence of n-dodecylamine [9]. These $\mathrm{CoSb}_{2} \mathrm{O}_{6}$ microspheres were sensitive to detect $400 \mathrm{ppm}$ of $\mathrm{CO}_{2}$ at $400{ }^{\circ} \mathrm{C}$ with a response time of $130 \mathrm{~s}$ and a recovery time of $22 \mathrm{~s}$. Also, the variation in electrical resistance recorded was $130 \Omega$. In addition, the dynamic response of $\mathrm{CoSb}_{2} \mathrm{O}_{6}$ prepared by solution-polymerization method has been reported [21]. In this paper, a $\mathrm{CO}_{2}$ flow $\left(100 \mathrm{~cm}^{3} / \mathrm{min}\right)$ produces an increase in electrical resistance of $900 \Omega$ in 3 min $\left(410{ }^{\circ} \mathrm{C}\right)$. However, the $\mathrm{CoSb}_{2} \mathrm{O}_{6}$ oxide synthesized in this work exhibits good sensing properties at lower temperatures $\left(250\right.$ and $\left.300{ }^{\circ} \mathrm{C}\right)$ to those reported in the previous works. Additionally, a faster response, shorter recovery times, better repeatability and larger impedance changes were obtained. This gas response can be attributed to the microstructure found in this work, and its nanocrystalline nature.

Moreover, from Figures 4 and 5 the rise of $|Z|$ during the flow of $\mathrm{CO}_{2}$ indicates a p-type semiconductor [31,32]. In general, the gas-sensing mechanism in semiconductor materials is based on the electric resistance change (conductance) produced by the electron transfer occurring during the chemical adsorption [32]. In the presence of a gas, such as the one used in this study $\left(\mathrm{CO}_{2}\right)$, electrons are provided to the oxide surface and they combine with holes. Therefore, the concentration of electrical charge carriers (holes) is reduced and the magnitude $|Z|$ increases. The process of $\mathrm{CO}_{2}$ adsorption on metal oxide surfaces can involve the formation of several carbon species, such as 
bicarbonate and carbonates [33]. These carbon species are removed when air is injected. Then, the magnitude $|Z|$ reached its original value.

Depending on the type of the semiconductor, the concentration of the charge carriers on the surface can be increased or decreased [34]. The thickness of the charged $L_{S}$ outer layer can be defined as [34]:

$$
L_{S}=L_{D} \sqrt{\frac{e V_{S}^{2}}{k T}}
$$

where $L_{D}$ is the Debye length, $e$ is the charge of the electron, $V_{S}$ is the potential of the surface, $k$ is the Boltzmann constant, and $T$ is the temperature. Usually, the $L_{S}$ values are between 1 and $100 \mathrm{~nm}$ [34].

According to some authors, the charged outer layer mainly depends on the gas pressure and the gas concentrations. These results of the changing resistance value and the conductivity variation of the semiconductor can be consulted in [35]. Due to this, the conductivity strongly depends on the size of the crystal $(D)$, thus giving rise to three possible scenarios [36]:

(1) If $D \gg 2 L_{S}$, the conductivity is limited by the Schottky barrier at the particle border; thus, the gas detection does not depend on the crystal size $(D)$,

(2) If $D=2 L_{S}$, the conductivity and the gas sensing depend on necks formed by the crystals, and

(3) If $D<2 L_{S}$, the conductivity depends on the crystal size [36,37]. Based on these three scenarios, it can be said that the smaller the size of the particle during its synthesis, the greater the surface area obtained and, therefore, a better gas adsorption [34].

In addition, the good electric response of the $\mathrm{CoSb}_{2} \mathrm{O}_{6}$ under a controlled air/ $\mathrm{CO}_{2}$ flow can be to a great extent explained by the presence of microstructures obtained during the process of synthesis.

\section{Conclusions}

Desirable trirutile-type $\mathrm{CoSb}_{2} \mathrm{O}_{6}$ structures for gas-sensing applications, like micro-rods and micro-bars, were successfully prepared by a wet-chemical synthesis route at relative low temperatures. The results of this work, regarding the sensing properties of the synthesized material, show that at different frequencies, the dynamic response improves under air/ $\mathrm{CO}_{2}$ flows. The $\mathrm{CoSb}_{2} \mathrm{O}_{6}$ thick films respond faster and with a shorter recovery time at higher temperatures and frequencies $(100 \mathrm{kHz}$ and $300{ }^{\circ} \mathrm{C}$ ). Also, the results indicated that increasing the frequency, smaller $|Z|$ values were obtained. The uniformity of the dynamic tests reflects the good impedance response during the adsorption of the $\mathrm{CO}_{2}$. According to this, the $\mathrm{CoSb}_{2} \mathrm{O}_{6}$ oxide is a strong candidate to be applied as an environmental gas sensor, especially when synthesized by our proposed method.

\section{Acknowledgments}

Alex Guillén-Bonilla acknowledges to Consejo Nacional de Ciencia y Tecnología (CONACyT) for the scholarship received. Authors express their gratitude to Carlos Michel-Uribe for giving us the possibility to use his facilities. 


\section{Author Contributions}

Verónica-María Rodríguez-Betancourtt was the supervisor of the $\mathrm{PhD}$ work of the author (Alex Guillén-Bonilla), from which this study results and contributed with work on the Raman spectroscopy analysis and the writing of this article; Martín Flores-Martínez contributed with work on the XRD analysis; Oscar Blanco-Alonso contributed with work on the gas-sensing tests; Juan Reyes-Gómez contributed with work on the SEM; Lorenzo Gildo-Ortiz contributed on observations, recommendations, discussion and a critical review of the manuscript; Héctor Guillén-Bonilla contributed with work on the synthesis method and the writing of this article. All authors read and approved the final manuscript.

\section{Conflicts of Interest}

The authors declare no conflict of interest.

\section{References}

1. Wang, C.; Yin, L.; Zhang, L.; Xiang, D.; Gao, R. Metal oxide gas sensors: Sensitivity and influencing factors. Sensors 2010, 10, 2088-2106.

2. Gómez-Pozos, H.; González-Vidal, J.L.; Torres, G.A.; Olvera, M.L.; Castañeda, L. Physical characterization and effect of effective surface area on the sensing properties of tin dioxide thin solid films in a propane atmosphere. Sensors 2014, 14, 403-415.

3. Gómez-Pozos, H.; González-Vidal, J.L.; Torres, G.A.; Rodríguez-Baez, J.; Maldonado, A.; Olvera, M.L.; Acosta, D.R.; Avendaño-Alejo, M.; Castañeda, L. Chromium and ruthenium-doped zinc oxide thin films for propane sensing applications. Sensors 2013, 13, 3432-3444.

4. Zhao, J.; Liu, Y.; Li, X.; Lu, G.; You, L.; Liang, X.; Liu, F.; Zhang, T.; Du, Y. Highly sensitive humidity sensor based on high surface area mesoporous $\mathrm{LaFeO}_{3}$ prepared by a nanocasting route. Sens. Actuators B Chem. 2013, 181, 802-809.

5. Li, Z.; Ding, D.; Liu, Q.; Ning, C. Hydrogen sensing with Ni-doped $\mathrm{TiO}_{2}$ nanotubes. Sensors 2013, 13, 8393-8402.

6. Gui, Y.; Yuan, J.; Wang, W.; Zhao, J.; Tian, J.; Xie, B. Facile solvothermal synthesis and gas sensitivity of graphene/ $\mathrm{WO}_{3}$ nanocomposites. Materials 2014, 7, 4587-4600.

7. Michel, C.R. $\mathrm{CO}$ and $\mathrm{CO}_{2}$ gas sensing properties of mesoporous $\mathrm{CoAl}_{2} \mathrm{O}_{4}$. Sens. Actuators $B$ Chem. 2010, 147, 635-641.

8. Michel, C.R.; Martínez, A.H.; Morán, J.P. Effect of the frequency on the gas sensing response of $\mathrm{CoSb}_{2} \mathrm{O}_{6}$ prepared by a colloidal method. Sens. Actuators B Chem. 2009, 140, 149-154.

9. Michel, C.R.; Guillén, H.; Martínez, A.H.; Morán, J.P. Synthesis and gas sensing properties of $\mathrm{CoSb}_{2} \mathrm{O}_{6}$ microspheres. Sens. Actuators B Chem. 2009, 143, 278-285.

10. Tamaki, J.; Yamada, Y.; Yamamoto, Y.; Matsuoka, M.; Ota, I. Sensing properties to dilute hydrogen sulfide of $\mathrm{ZnSb}_{2} \mathrm{O}_{6}$ thick-film prepared by dip-coating method. Sens. Actuators $B$ Chem. 2000, 66, 70-73.

11. Zhu, B.L.; Xie, C.S.; Wang, A.H.; Zeng, D.W.; Hu, M.L.; Wang, W.Y. Electrical conductivity and gas sensitivity of Zn-Sb-O thick films. Mater. Res. Bull. 2004, 39, 409-415. 
12. Jung, W.Y.; Hong, S.S. Synthesis of $\mathrm{LaCoO}_{3}$ nanoparticles by microwave process and their photocatalytic activity under visible light irradiation. J. Ind. Eng. Chem. 2013, 19, 157-160.

13. Sompech, S.; Srion, A.; Nuntiya, A. The effect of ultrasonic treatment on the particle size and specific surface area of $\mathrm{LaCoO}_{3}$. Procedia Eng. 2012, 32, 1012-1018.

14. Khun, K.; Ibupoto, Z.H.; AlSalhi, M.S.; Atif, M.; Ansari, A.A.; Willander, M. Fabrication of well-aligned $\mathrm{ZnO}$ nanorods using a composite seed layer of $\mathrm{ZnO}$ nanoparticles and chitosan polymer. Materials 2013, 6, 4361-4374.

15. Mei, L.; Deng, J.; Yin, X.; Zhang, M.; Li, Q.; Zhang, E.; Xu, Z.; Chen, L.; Wang, T. Ultrasensitive ethanol sensor based on $3 \mathrm{D}$ aloe-like $\mathrm{SnO}_{2}$. Sens. Actuators B Chem. 2012, $166,7-11$.

16. Jamal, A.; Rahman, M.M.; Khan, S.B.; Faisal, M.; Akhtar, K.; Rub, M.A.; Asiri, A.M.; Al-Youbi, A.O. Cobalt doped antimony oxide nano-particles based chemical sensor and photo-catalyst for environmental pollutants. Appl. Surf. Sci. 2012, 261, 52-58.

17. Mizoguchi, H.; Woodward, P.M. Electronic structure studies of main group oxides possessing edge-sharing octahedra: implications for the design of transparent conducting oxides. Chem. Mater. 2004, 16, 5233-5248.

18. Delgado, E.; Michel, C.R. $\mathrm{CO}_{2}$ and $\mathrm{O}_{2}$ sensing behavior of nanostructured barium-doped $\mathrm{SmCoO}_{3}$. Mater. Lett. 2006, 60, 1613-1616.

19. Holzwarth, U.; Gibson, N. The Scherrer equation versus the 'Debye Scherrer equation'. Nat. Nanotechnol. 2011, 6, doi:10.1038/nnano.2011.145.

20. Larcher, D.; Prakash, A.S.; Laffont, L.; Womens, M.; Jumas, J.C.; Olivier-Fourcade, J.; Hedge, M.S.; Tarascon, J.-M.M. Reactivity of antimony oxides and $\mathrm{MSb}_{2} \mathrm{O}_{6}(\mathrm{M}=\mathrm{Cu}, \mathrm{Ni}, \mathrm{Co})$, trirutile-type phases with metallic lithium. J. Electrochem. Soc. 2006, 153, A1778-A1787.

21. Michel, C.R.; Martínez, A.H.; Jiménez, S. Gas sensing response of nanostructured trirutile-type $\mathrm{CoSb}_{2} \mathrm{O}_{6}$ synthesized by solution-polymerization method. Sens. Actuators B Chem. 2008, 132, $45-51$.

22. Haeuseler, H. Infrared and Raman spectra and normal coordinate calculations on trirutile-type compounds. Spectrochim. Acta Part A Mol. Spectrosc. 1981, 37, 487-495.

23. Husson, E.; Repelin, Y.; Brusset, H.; Cerez, A. Spectres de vibration et calcul du champ de force des antimoniates et des tantalates de structure trirutile. Spectrochim. Acta Part A Mol. Spectrosc. 1979, 35, 1171-1187. (in French)

24. Gildo-Ortiz, L.; Guillén-Bonilla, H.; Santoyo-Salazar, J.; Olvera, M.L.; Karthik, T.V.K.; Campos-González, E.; Reyes-Gómez, J. Low-temperature synthesis and gas sensitivity of perovskite-type $\mathrm{LaCoO}_{3}$ nanoparticles. J. Nanomater. 2014, 2014, doi: org/10.1155/2014/164380.

25. Deng, Z.-X.; Wang, C.; Sun, X.-M.; Li, Y.D. Structure-directing coordination template effect of ethylenediamine in formations of $\mathrm{ZnS}$ and $\mathrm{ZnSe}$ nanocrystallites via solvothermal route. Inorg. Chem. 2002, 41, 869-873.

26. Wang, X.; Li, Y. Solution-based synthetic strategies for 1-D nanostructures. Inorg. Chem. 2006, $45,7522-7534$.

27. Guillén, H.; Reyes, J.; Guillén, A.; Pozas, D.; Guillén, J.T.; Gildo, L.; Flores, M. Synthesis and characterization of $\mathrm{MgSb}_{2} \mathrm{O}_{6}$ trirutile-type in low presence concentrations of ethylenediamine. J. Chem. Chem. Eng. 2013, 7, 395-401. 
28. Matijevic, E. Uniform inorganic colloid dispersions. Achievements and challenges. Langmuir 1994, 10, 8-16.

29. Matijevic, E. Monodispersed colloids: Art and science. Langmuir 1986, 2, 12-20.

30. LaMer, V.K.; Dinegar, R.H. Theory, production and mechanism of formation of monodispersed hydrosols. J. Am. Chem. Soc. 1950, 72, 4847-4854.

31. Michel, C.R.; Martínez-Preciado, A.M.; Morán-Lázaro, J.P.; Guillén-Bonilla, H. $\mathrm{CO}_{2}$ detection in nanostructured $\mathrm{CoSb}_{2} \mathrm{O}_{6}$ prepared by a non-aqueous colloidal method. ECS Trans. 2010, 25, 49-51.

32. Moseley, P.T. Materials selection for semiconductor gas sensors. Sens. Actuators B Chem. 1992, 6, 149-156.

33. Tsuji, H.; Okamura-Yoshida, A.; Shishido, T.; Hattori, H. Dynamic behavior of carbonate species on metal oxide surface: Oxygen scrambling between adsorbed carbon dioxide and oxide surface. Langmuir 2003, 19, 8793-8800.

34. Bochenkov, V.E.; Sergeev, G.B. Preparation and chemiresistive properties of nanostructured materials. Adv. Colloid Interface Sci. 2005, 116, 245-254.

35. Michel, C.R.; Delgado, E.; Martínez, A.H. Evidence of improvement in gas sensing properties of nanostructured bismuth cobaltite prepared by solution-polymerization method. Sens. Actuators $B$ Chem. 2007, 125, 389-395.

36. Yamazoe, N. New approaches for improving semiconductor gas sensors. Sens. Actuators B Chem. 1991, 5, 7-19.

37. Yamazoe, N. Toward innovations of gas sensor technology. Sens. Actuators B Chem. 2005, $108,2-14$.

(C) 2014 by the authors; licensee MDPI, Basel, Switzerland. This article is an open access article distributed under the terms and conditions of the Creative Commons Attribution license (http://creativecommons.org/licenses/by/3.0/). 